\title{
Wavelength Dependence of Photooxidation vs Photofragmentation of Chromocene
}

\author{
Peter T. Muraoka, Daniel Byun, and Jeffrey I. Zink* \\ Department of Chemistry and Biochemistry, University of California, Los Angeles, California 90095
}

Received: March 19, 2001; In Final Form: July 2, 2001

\begin{abstract}
Photooxidation and metal-ligand photolysis reactions of bis(cyclopentadienyl)chromium, chromocene, in the range $24390-15630 \mathrm{~cm}^{-1}$ are studied in the gas phase by using time-of-flight mass spectroscopic detection. Photooxidation of the intact chromocene molecule unexpectedly dominates in the range $23530-24000 \mathrm{~cm}^{-1}$. The relative importance of photooxidation compared to photofragmentation is strongly wavelength dependent. A prominent species at all wavelengths is the chromium ion, but in a wavelength region corresponding to the lowest energy ligand to metal charge transfer excited electronic state absorption, the strongest peak is from the chromocene ion. The excitation spectra are reported for three selected species: chromocene ion, mono(cyclopentadienyl)chromium ion, and the chromium ion. The spectrum obtained by monitoring the metal ion contains sharp peaks that are assigned to neutral chromium atom resonances. Sharp losses of intensities in the molecular ion spectra are observed at these wavelengths. The wavelength dependencies of the photoreactions are interpreted and explained in terms of the identity of the initially populated excited electronic state and the ionization energy of the molecule. When the initially populated excited electronic state is the ligand to metal charge transfer state, the first photon causes minimal bond weakening and the second photon excites the intact chromocene above the ionization energy, resulting in efficient ionization of the parent molecule. When the initially populated state is a lower energy ligand field excited electronic state, bond weakening occurs and absorption of a second photon results in significant photodissociation producing intense fragment peaks dominated by the metal ion peak.
\end{abstract}

\section{Introduction}

The gas phase photochemical reactions of metal compounds, and especially the primary photochemical processes such as photodissociation and photofragmentation, are attracting interest because of their importance in understanding laser assisted chemical vapor deposition. ${ }^{1-5}$ Identification and quantification of the photofragments use luminescence spectroscopy and mass spectroscopy as the primary analytical methods. ${ }^{6-10}$ Our interest in the photochemistry was sparked by our observations that both desired photofragments (i.e., those having the stoichiometry of the desired deposit) and undesired species (i.e., those that lead to contamination of the desired deposit) are produced by intramolecular processes in the gas phase. ${ }^{11-13}$ The amounts of the photofragments that are produced depend on both the wavelength and the fluence of the exciting light. In our studies of chromium metal deposition using tris(hexafluoroacetylacetonate)chromium, $\mathrm{Cr}$ (hfac) $)_{3}$, as the precursor, we discovered that chromium atoms are readily formed by photolysis but that significant amounts of the undesired diatomic photofragment $\mathrm{CrF}$ were also produced intramolecularly. ${ }^{14,15}$ To avoid fluorine contamination of the deposit, we investigated other chromium precursors including chromocene, bis(cyclopentadienyl)chromium, $\mathrm{Cr}(\mathrm{Cp})_{2}$.

Multiphoton dissociation of many metallocene compounds has been studied by mass spectroscopy. ${ }^{16-27}$ The wavelength dependence of the total ion current spectrum for ferrocene and cobaltocene in the ranges 366-370, 380-390, and 445-455 $\mathrm{nm}$ and for nickelocene in the range $375-520 \mathrm{~nm}$ was reported. ${ }^{20,24,25}$ The features in the excitation spectrum were attributed solely to the metal ion. "Explosive" dissociation directly to the metal was the most commonly observed photolytic pathway. In studies of ferrocene in the UV/vis region, no ferrocene cations were detected. ${ }^{17,19-21,24,25}$ However, in the VUV at $193 \mathrm{~nm}$ excitation, the parent ion is observed. ${ }^{16,26,27}$ Similar results were reported for nickelocene. The largest reported ratio of parent ion to metal ion intensities in multiphoton ionization of a metallocene was $0.005: 1$ for nickelocene. ${ }^{21}$ The only reported multiphoton dissociation/ionization studies of chromocene employed emission spectroscopy to detect the excited-state photoproducts after excitation at $248 \mathrm{~nm} .{ }^{28}$ Only emission from atomic $\mathrm{Cr}$ was detected.

In this paper, we report the surprising discovery that chromocene ion can be the major product of gas-phase photolysis and that the ratio of chromocene ion to the chromium $\mathrm{Cr}^{+}$ion is strongly wavelength dependent. We examine this result by using time-of-flight mass spectroscopy and resonance enhanced multiphoton ionization (REMPI) spectroscopy. Excitation within a narrow wavelength range results in photooxidation to produce the molecular ion and fragmentation that includes formation of the monoligated chromium species, the cyclopentadienyl ion, the chromium ion, and small carbon fragments of the ligand. Outside of this wavelength range, complete metal-ligand photolysis occurs and the dominant mass signal is $\mathrm{Cr}^{+}$. Both broad bands and sharp lines in the mass-selected excitation spectra are observed. The wavelength regions that lead to specific fragments are correlated to absorption bands of chromocene and the fragmentation patterns are interpreted in terms of the bonding changes that occur in the initially populated excited state. The sharp lines arise from neutral chromium atom absorption bands.

\section{Experimental Section}

The TOF mass spectrometer was constructed based on a design in the literature. ${ }^{29,30}$ The chromocene (Aldrich, 95\%) is 
admitted to the high-vacuum chamber via a supersonic jet. The base pressure of the chamber is less than $10^{-6}$ Torr. The photoionization for mass spectroscopy is carried out in a stainless steel cube (30 cm edge length) with quartz windows evacuated to $10^{-6}$ Torr with a 12 in. diffusion pump fitted with a water-cooled baffle. The sample is sublimed at $85{ }^{\circ} \mathrm{C}$ before it is seeded in He with a backing pressure of about $10^{3}$ Torr. A General Valve series 9 high-speed solenoid valve $(0.5 \mathrm{~mm}$ orifice) sends a $0.2 \mathrm{~ms}$ pulse of the sample into the chamber to intersect the incoming photons at $90^{\circ}$. An optical parametric oscillator pumped by the third harmonic of a Nd:YAG laser produces the photons within the $24390-15630 \mathrm{~cm}^{-1}$ range ( $\sim 20 \mathrm{~mJ} /$ pulse, $10-20 \mathrm{~cm}^{-1}$ line width) used for excitation. The laser fluence was only varied in our power dependence studies. The energy range is scanned with a stepping motor driven micrometer that tunes the crystal of the OPO. The wavelength of the OPO output is calibrated with a monochromator and a CCD detector. The total experimental uncertainty in the reported photon energies is $\pm 10 \mathrm{~cm}^{-1}$.

The fragment ions are accelerated down a $1 \mathrm{~m}$ flight tube by a series of three stainless steel plates that have stainless steel mesh across an open center. Acceleration plate voltages are 3000 $\mathrm{V}, 2100 \mathrm{~V}$, and ground, respectively, in order from furthest to nearest the detector. The flight tube is kept at $10^{-6}$ Torr using a Varian V300HT 6 in. air-cooled turbomolecular pump, and ions are detected using an $18 \mathrm{~mm}$ microchannel plate detector assembly. The detector assembly is fitted with two Galileo MCP $18 \mathrm{~B}$ plates with a $10 \mu \mathrm{m}$ channel diameter and a channel spacing of $12.5 \mu \mathrm{m}$. The ion current is processed using a computercontrolled RTD710 Tektronix $200 \mathrm{MHz}$ dual-channel digitizer. A variable delay Stanford Research Systems model SR250 Gated Integrator and Boxcar Averager Module is used for the wavelength dependence studies.

\section{Results}

1. Mass Spectra. a. General Trends and Observations. A strong feature that is common to all of the mass spectra at all of the wavelengths used for fragmentation and ionization is the group of peaks arising from $\mathrm{Cr}^{+}$. The peaks are observed at $50,52,53$, and $54 \mathrm{~m} / \mathrm{z}$ and correspond to the most abundant isotopes of chromium. When maximizing the intensity of the minor fragments, the intensities of the dominant $\mathrm{Cr}^{+}$and $\mathrm{Cr}(\mathrm{Cp})_{2}{ }^{+}$become saturated. Mass spectra taken at three representative wavelengths are shown in Figure 1.

The relative intensities of the peaks in the mass spectrum are very wavelength dependent. At photon energies less than about $23530 \mathrm{~cm}^{-1}$, the peaks from $\mathrm{Cr}^{+}$dominate the spectrum; all other peaks are less than $1 / 12$ as intense. In the wavelength region between 21000 and $23530 \mathrm{~cm}^{-1}$, the peaks from $\mathrm{Cr}^{+}$ are the most intense but peaks from the parent ion and $\mathrm{Cr}(\mathrm{Cp})^{+}$ appear with intensities about $6 \%$ that of the metal ion. In the energy region from 23530 to $24390 \mathrm{~cm}^{-1}$ (the limit of the scanning range of the instrument), the intensity of the parent ion peak is about the same as that of the metal ion. At an energy of $28170 \mathrm{~cm}^{-1}$ (the third harmonic of the Nd:YAG laser), the $\mathrm{Cr}^{+}$peaks again dominate the mass spectrum and the next most intense peaks arise from $\mathrm{C}_{1}{ }^{+}, \mathrm{C}_{2}{ }^{+}$, and $\mathrm{C}_{3}{ }^{+}$fragments of the ligands with intensities roughly $1 / 4$ to $1 / 3$ that of the metal ion. Representative mass spectra obtained by exciting chromocene at specific wavelengths within these regions are shown in Figure 1 and are described in detail below.

b. $21170 \mathrm{~cm}^{-1}$ (472 $\mathrm{nm}$ ) Excitation. Figure 1a is representative of the spectra obtained in the $21000-23530 \mathrm{~cm}^{-1}$ region. The mass spectra obtained at energies lower than $21000 \mathrm{~cm}^{-1}$
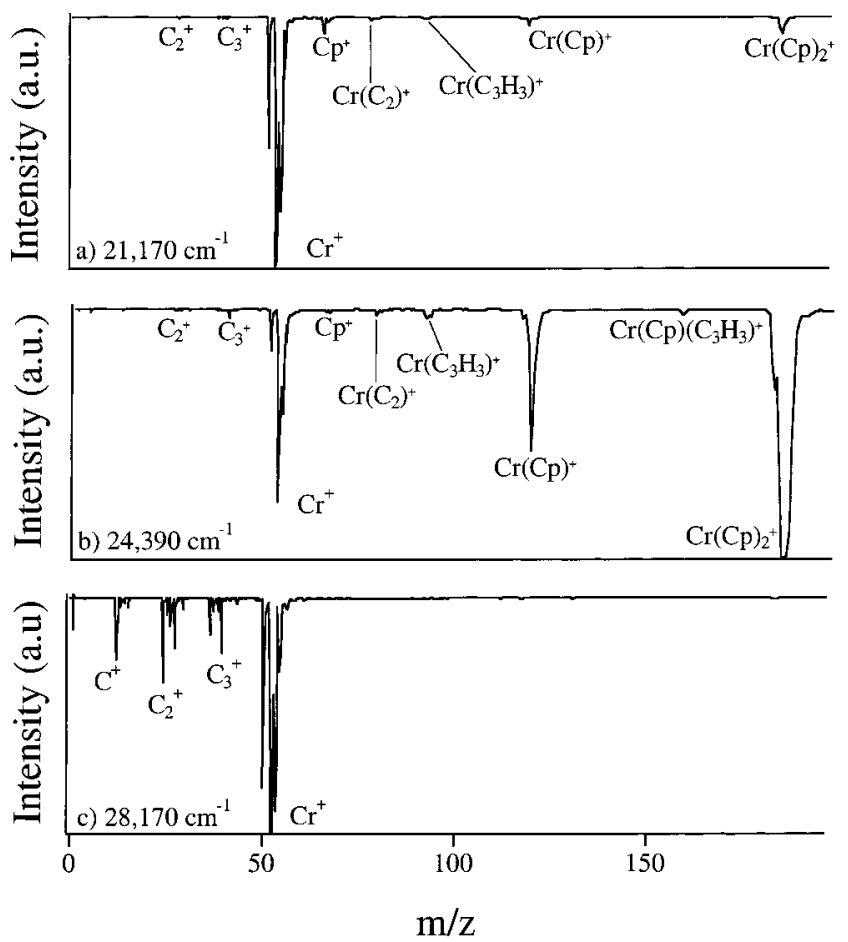

Figure 1. Mass spectra resulting from photolysis of chromocene at (a) $21170 \mathrm{~cm}^{-1}$, (b) $24390 \mathrm{~cm}^{-1}$, and (c) $28170 \mathrm{~cm}^{-1}$. The three peaks appearing at 50,52 , and $53 \mathrm{~m} / \mathrm{z}$ correspond to the isotopes of chromium.

outside this scan region are dominated mostly by $\mathrm{Cr}^{+}$and fragments of the $\mathrm{Cp}$ group, whereas $\mathrm{Cr}(\mathrm{Cp})_{2}{ }^{+}$is observed at $<1 / 15$ the intensity of the metal ion. However, numerous chromium-containing molecular species, including $\mathrm{Cr}(\mathrm{Cp})_{2}{ }^{+}$and $\mathrm{Cr}(\mathrm{Cp})^{+}$begin to appear in the scan to higher energies in the region $21000-23530 \mathrm{~cm}^{-1}$. The appearance of other metalcontaining fragments including $\mathrm{CrC}_{2}^{+}$and $\mathrm{CrC}_{3} \mathrm{H}_{3}{ }^{+}$is also evident although the spectra are still dominated by $\mathrm{Cr}^{+}$. At the highest energy region within this scanning range, the molecular peak intensities increase in intensity and never decrease to the intensities observed at lower energies.

c. $24390 \mathrm{~cm}^{-1}(410 \mathrm{~nm})$ Excitation. Figure $1 \mathrm{~b}$ is representative of the spectra in the region $23530-24390 \mathrm{~cm}^{-1}$. This fragmentation pattern is unexpected because the chromiumcontaining molecular species $\mathrm{Cr}(\mathrm{Cp})_{2}{ }^{+}$and $\mathrm{Cr}(\mathrm{Cp})^{+}$have intensities comparable to that of the $\mathrm{Cr}^{+}$ion. A list of the fragment peaks observed and their intensities relative to $\mathrm{Cr}^{+}$ are reported in Table 1. To the best of our knowledge, this spectrum is the first observation of multiphoton ionization of the intact molecule, and other large molecular ion species, to such a large degree. $\mathrm{Cr}^{+}$is also observed, but unlike mass spectral data obtained from other metallocenes in this energy region, the molecular ion dominates the mass spectrum.

d. $28170 \mathrm{~cm}^{-1}(355 \mathrm{~nm})$ Excitation. Figure 1c shows a mass spectrum obtained at a point to higher energy outside the scan region. The spectrum contains fragments of the $\mathrm{Cp}$ ring as well as a detectable amount of $\mathrm{Cr}(\mathrm{Cp})^{+}$but it is dominated by chromium ions; the relative intensities of the next biggest peak $\left(\mathrm{C}_{2}{ }^{+}\right)$is about one-fifth that of chromium. The cyclopentadienyl ligand itself is extensively fragmented. Other fragments are observed and their intensities relative to $\mathrm{Cr}^{+}$are listed in Table 1. This complete fragmentation to the metal ion is typical of the patterns reported for photolysis of organometallic compounds.

2. Wavelength Dependence of Photolysis by Mass-Selected REMPI Spectroscopy. The intensities of specific mass peaks 
TABLE 1: Mass Peaks Observed during UV and Visible Wavelength Photolysis of Chromocene ${ }^{a}$

\begin{tabular}{|c|c|c|c|}
\hline ion $^{+}$ & $21170 \mathrm{~cm}^{-1}$ & $24390 \mathrm{~cm}^{-1}$ & $28170 \mathrm{~cm}^{-1}$ \\
\hline $\mathrm{C}$ & & & 17 \\
\hline $\mathrm{CH}$ & & & 2 \\
\hline $\mathrm{CH}_{2}$ & & & 1 \\
\hline $\mathrm{CH}_{3}$ & & & 2 \\
\hline $\mathrm{C}_{2}$ & & & 21 \\
\hline $\mathrm{C}_{2} \mathrm{H}$ & & & 4 \\
\hline $\mathrm{C}_{2} \mathrm{H}_{2}$ & & & 7 \\
\hline $\mathrm{C}_{2} \mathrm{H}_{3}$ & $<1$ & $<1$ & 12 \\
\hline $\mathrm{C}_{2} \mathrm{H}_{4}$ & & & $<1$ \\
\hline $\mathrm{C}_{2} \mathrm{H}_{5}$ & & & 3 \\
\hline $\mathrm{C}_{3}$ & & & 9 \\
\hline $\mathrm{C}_{3} \mathrm{H}$ & & & 3 \\
\hline $\mathrm{C}_{3} \mathrm{H}_{2}$ & & & 3 \\
\hline $\mathrm{C}_{3} \mathrm{H}_{3}$ & 2 & 5 & 15 \\
\hline $\mathrm{C}_{3} \mathrm{H}_{4}$ & & & $<1$ \\
\hline $\mathrm{C}_{3} \mathrm{H}_{5}$ & & & $<1$ \\
\hline $\mathrm{C}_{3} \mathrm{H}_{7}$ & & & 1 \\
\hline $\mathrm{Cr}$ & 100 & 100 & 100 \\
\hline $\mathrm{C}_{5} \mathrm{H}_{5}(\mathrm{Cp})$ & 8 & 2 & \\
\hline $\mathrm{CrC}_{2}$ & 1 & 3 & \\
\hline $\mathrm{CrC}_{3} \mathrm{H}_{3}$ & 0.6 & 4.5 & \\
\hline $\mathrm{CrCp}$ & 3.1 & 74.0 & \\
\hline $\mathrm{CrCpC}_{3} \mathrm{H}_{3}$ & & 2.8 & \\
\hline $\mathrm{Cr}(\mathrm{Cp})_{2}$ & 6.4 & 138.1 & \\
\hline
\end{tabular}

${ }^{a}$ The intensities are calculated relative to that of $\mathrm{Cr}^{+}$. All peaks with intensities greater than 0.003 that of $\mathrm{Cr}^{+}$are listed

are measured as a function of the photon energy in order to obtain more detailed information about the wavelength dependencies. The plots, or REMPI spectra, that are obtained when the $\mathrm{Cr}^{+}, \mathrm{Cr}(\mathrm{Cp})^{+}$, and $\mathrm{Cr}(\mathrm{Cp})_{2}{ }^{+}$ions are monitored are shown in Figure 2.

Chromium Ion. The wavelength dependence of the intensity of $\mathrm{Cr}^{+}$from chromocene photolysis throughout the $21500-$ $24000 \mathrm{~cm}^{-1}$ range is shown in Figure 2c. The spectrum is relatively flat between $21500-22000 \mathrm{~cm}^{-1}$. As the laser is scanned beyond this range to higher energies, the $\mathrm{Cr}^{+}$signal increases and the resulting spectrum is full of sharp features. The spectrum has a downward slope between 23 530-24 000 $\mathrm{cm}^{-1}(425-417 \mathrm{~nm})$ except for the presence of a sharp peak at $23830 \mathrm{~cm}^{-1}$. For reasons that are discussed later, the sharp peaks are assigned to the ionization of neutral chromium atoms from atomic resonant states.

$\mathrm{Cr}(\mathrm{Cp})^{+}$. The REMPI spectrum obtained by monitoring $\mathrm{Cr}(\mathrm{Cp})^{+}$in Figure $2 \mathrm{~b}$ shows a relatively flat nonzero signal in the range $21500-23530 \mathrm{~cm}^{-1}$. The $\mathrm{Cr}(\mathrm{Cp})^{+}$intensity slowly increases as the laser is scanned to higher energies until the onset of a broad band in the $23530-24000 \mathrm{~cm}^{-1}$ range. The spectrum also shows a sharp dip in the $\mathrm{Cr}(\mathrm{Cp})^{+}$intensity at $23830 \mathrm{~cm}^{-1}$ along this rising band. This dip is also present in the REMPI spectrum of the intact molecular ion and coincides with a maximum in the $\mathrm{Cr}^{+}$spectrum.

$\mathrm{Cr}(\mathrm{Cp})_{2}{ }^{+}$. The REMPI spectrum obtained by monitoring $\mathrm{Cr}(\mathrm{Cp})_{2}{ }^{+}$in Figure 2a shows wavelength-dependent behavior very similar to that of $\mathrm{Cr}(\mathrm{Cp})^{+}$. However, the intensity of the $\mathrm{Cr}(\mathrm{Cp})_{2}{ }^{+}$signal is about 2 times greater than that of the $\mathrm{Cr}(\mathrm{Cp})^{+}$ ion. At energies lower than $23530 \mathrm{~cm}^{-1}$, the molecular ion signal intensities are small and relatively constant. The REMPI spectrum of $\mathrm{Cr}(\mathrm{Cp})_{2}{ }^{+}$also shows a gradual increase in the molecular ion signal between $23530-24000 \mathrm{~cm}^{-1}$. A scan in this range traces a broad band characteristic of molecular spectra but at $23830 \mathrm{~cm}^{-1}$ there is a dip in the spectrum that coincides with a maximum in the $\mathrm{Cr}^{+}$spectra. Comparison of the wavelength-dependent properties of $\mathrm{Cr}^{+}$and $\mathrm{Cr}(\mathrm{Cp})_{2}{ }^{+}$will play a major role in the following discussion.
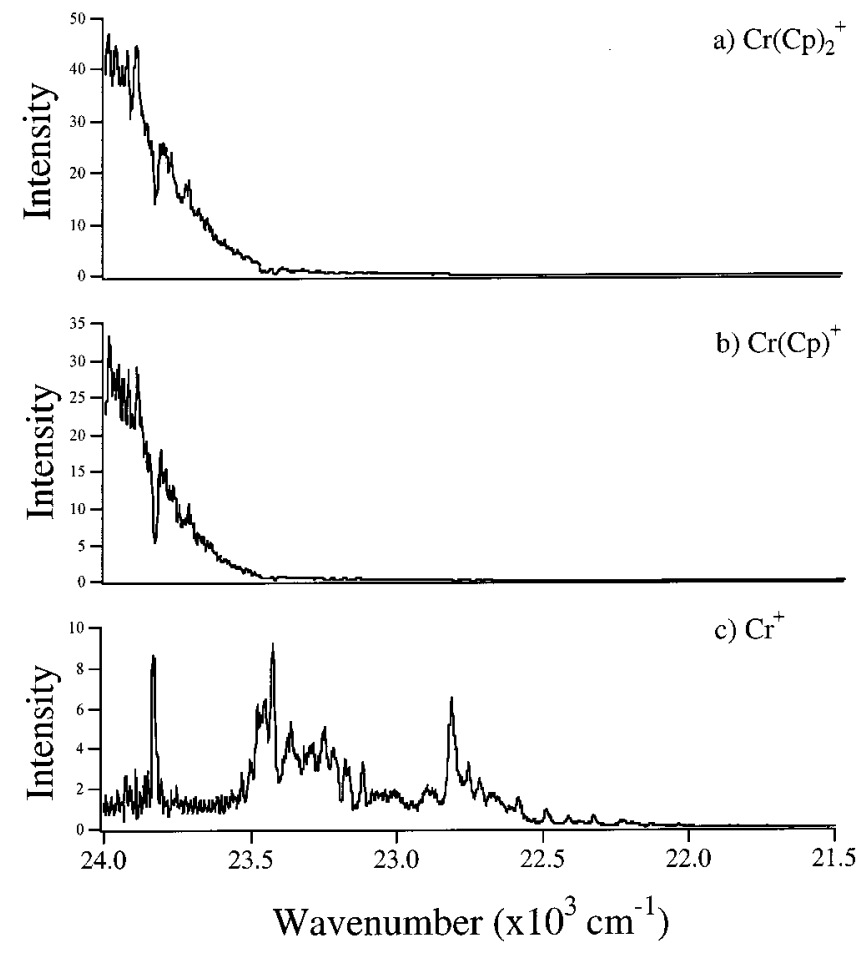

Figure 2. REMPI spectra obtained monitoring (a) $\mathrm{Cr}(\mathrm{Cp})_{2}{ }^{+}$, (b) $\mathrm{Cr}(\mathrm{Cp})^{+}$, and (c) $\mathrm{Cr}^{+}$. Note the different intensity scales.

3. Mass Spectra at Energies Corresponding to Sharp REMPI Peaks. 23660 vs $23490 \mathrm{~cm}^{-1}$ (423 nm vs $426 \mathrm{~nm}$ ) Excitation. Careful comparison of the $\mathrm{Cr}^{+}$and $\mathrm{Cr}(\mathrm{Cp})_{2}{ }^{+} \mathrm{REMPI}$ spectra shows that there are specific wavelengths where a maximum in the $\mathrm{Cr}^{+}$spectrum has a corresponding minimum in the $\mathrm{Cr}(\mathrm{Cp})_{2}{ }^{+}$spectrum. The most obvious peak and dip occur at $23830 \mathrm{~cm}^{-1}$. When the laser is tuned into a sharp peak in the REMPI spectrum, the $\mathrm{Cr}^{+}$ion signal is so strong that it saturates the ion detector as shown in Figure 3b. When the laser is tuned off of the sharp peak, both the $\mathrm{Cr}^{+}$and the $\mathrm{Cr}(\mathrm{Cp})_{2}{ }^{+}$ ion signals are of comparable intensity as shown in Figure $3 \mathrm{a}$. The surrounding mass peaks have about the same relative intensities in both cases.

4. Fluence Dependence of Photofragmentation. To study the effect of fluence, mass spectra were taken at varying laser pulse energies. In the $23500-21500 \mathrm{~cm}^{-1}$ range, the $\mathrm{Cr}^{+}$ intensity decreased more rapidly relative to the intensity of the metal-containing molecular fragments when the laser fluence decreased. The observed photon law was calculated by plotting the $\log$ of the intensity of the ion signal vs the log of the laser fluence (Figure 4). A two-photon power law is observed for production of the molecular ion at 21320 and $24260 \mathrm{~cm}^{-1}$. A two-photon power law is also observed for production of the chromium ion at energies above $\sim 23500 \mathrm{~cm}^{-1}$, whereas a fourphoton power law is observed at energies below $\sim 23500 \mathrm{~cm}^{-1}$. Because of saturation effects, more photons than are measured in the experimental photon power law may be involved. ${ }^{31}$

\section{Discussion}

1. Mass Spectroscopy. When a molecule is placed in an intense visible or UV laser field, multiphoton absorptions may occur and population of high energy states is possible. ${ }^{31-37}$ Molecules placed in this field may continue to absorb photons until the molecule loses its energy by emission, ionization, decomposition or radiationless transition. ${ }^{32,37}$ The mechanisms of multiphoton ionization and dissociation have been characterized by two different pathways: ladder climbing and ladder 

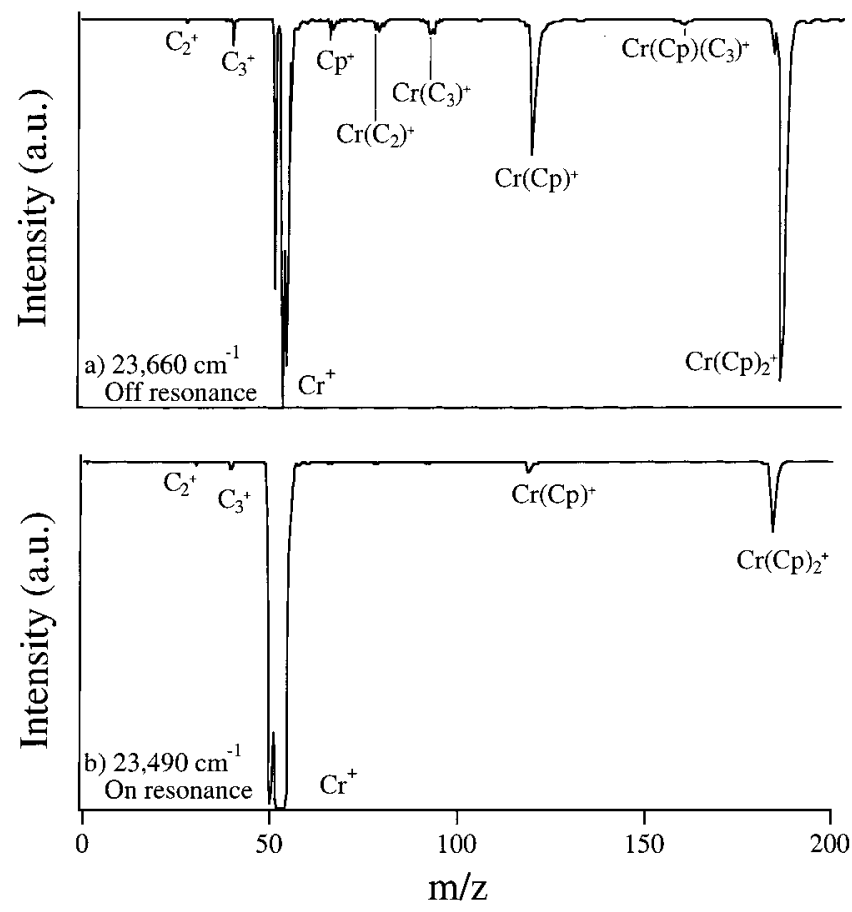

Figure 3. Mass spectra of chromocene a) off resonance $\left(23660 \mathrm{~cm}^{-1}\right)$ and (b) on resonance $\left(23490 \mathrm{~cm}^{-1}\right)$. Saturation of the detector at the position of the $\mathrm{Cr}^{+}$signal can be seen in the bottom spectrum. The peaks labeled as containing carbon species $\left(\mathrm{C}_{n}{ }^{+}\right)$actually contain the range of protonated $\mathrm{Cp}$ ring fragments $\left(\mathrm{C}_{n} \mathrm{H}_{1}\right)^{+}$to $\left(\mathrm{C}_{n} \mathrm{H}_{2 n+1}\right)^{+}$.

switching. ${ }^{31,37}$ Each pathway starts with photon absorption that places the molecule (or fragment) in an excited state. The former pathway involves absorption of additional photons until the ionization continuum is reached and parent ions are produced. The latter involves bond breaking before the parent molecule can be ionized; additional photon absorption processes ionize the fragments and the mass spectrum is dominated by fragment ion peaks. Most transition metal compounds possess relatively weak metal-ligand bonds and follow the ladder switching mechanism whereby one or more photons cause metal-ligand bond breaking before the parent molecule is ionized. The metal ion peak dominates the mass spectrum and the parent ion peak is usually very weak or absent.

The relative intensities of the intact chromocene ion in the mass spectra during visible excitation are somewhat surprising. In previous photolytic investigations of many other organometallic molecules, the intact molecular ion was rarely seen, and never before with an intensity similar to that of the metal ion. ${ }^{21}$ Photon initiated fragmentation studies found in the literature mainly report the observation of the metal ion and low mass fragments of the ligand. In addition to these species, we observe the intact molecular ion as well as other chromiumcontaining molecular fragments. Table 1 shows the relative intensities of the mass fragments observed during photodissociation of chromocene at $21170 \mathrm{~cm}^{-1}, 24390 \mathrm{~cm}^{-1}$, and 28170 $\mathrm{cm}^{-1}$. The ratios are determined relative to the most abundant isotope of chromium at $52 \mathrm{~m} / \mathrm{z}$. Correlations between the photofragmentation and specific spectral regions are discussed below.

Photodissociation at energies lower than $23530 \mathrm{~cm}^{-1}$ produces a fragmentation pattern that is typical of those previously reported for metallocenes, ${ }^{16-27}$ i.e., dominated by the metal ion. The occurrence of $\mathrm{Cr}$ atomic resonant ionization is predominant and is evidenced by the group of sharp peaks arising from $\mathrm{Cr}$ atomic transitions that are observed in the REMPI spectra in this region. However, other metal-containing species such as $\mathrm{Cr}(\mathrm{Cp})^{+}, \mathrm{CrC}_{2}{ }^{+}$, and $\mathrm{CrC}_{3} \mathrm{H}_{3}{ }^{+}$are observed but at less than $10 \%$ of the intensity of the chromium ion. It is relevant to note that the metal-carbon fragments mentioned above as well as the $\mathrm{C}_{n}{ }^{+}$fragments of the $\mathrm{Cp}$ ring $\left(\mathrm{C}_{2}{ }^{+}, \mathrm{C}_{3}{ }^{+}\right.$, etc. $)$represent the group of protonated species $\left(\mathrm{C}_{n} \mathrm{H}_{1}\right)^{+}$to $\left(\mathrm{C}_{n} \mathrm{H}_{2 n+1}\right)^{+}$.

At $21170 \mathrm{~cm}^{-1}$, the ratio of the monoligated fragment and the molecular ion to that of the metal ion are roughly $0.03: 1$ and $0.06: 1$, respectively. The favored mechanism in this region most likely involves photodissociation of chromocene before it is excited above the ionization continuum. The spectra in this region are characteristic of those observed in other metallocenes as there is a very intense signal from the metal ion and weak or undetectable signals from the intact metal-containing molecular species. ${ }^{12,21,38}$

In the $24390 \mathrm{~cm}^{-1}$ spectrum, the fragmentation pattern is similar to that observed in the mass spectrum at $21170 \mathrm{~cm}^{-1}$. However, the relative intensities of the metal-containing molecular fragments have noticeably increased from the spectra at lower energies. Both the molecular ion and the monoligated fragment intensities have increased by a factor of 20 compared to those in the spectrum obtained at $21170 \mathrm{~cm}^{-1}$. The molecular ion intensity is now greater than the intensity of the metal ion. The presence of a molecular ion signal implies that ionization of chromocene occurs before the molecule dissociates. Fragmentation of the ionized molecule may then occur by sequential ligand loss until $\mathrm{Cr}^{+}$is produced. This mechanism is also supported by the presence of the intense signals from the monoligated and the free ligand ions.

The intensities of the $\mathrm{C}_{n}{ }^{+}$cyclopentadienyl fragments are similar at the energies discussed so far but the increase in intensity of the $\mathrm{Cr}\left(\mathrm{C}_{3} \mathrm{H}_{3}\right)^{+}$and $\mathrm{CrC}_{2}{ }^{+}$fragments may be a direct result of the increased amount of the corresponding monoligated species formed during the photodissociation process. The metal atom may be bonded to the cyclopentadienyl moiety in an allyllike fashion after excitation. The formation of $\mathrm{Cr}\left(\mathrm{C}_{3} \mathrm{H}_{3}\right)^{+}$and $\mathrm{CrC}_{2}{ }^{+}$then suggests an intramolecular process by which the cyclopentadienyl ring of the monoligated species fragments to leave behind allyl- and ethylene-like bonded fragments. To the best of our knowledge, this is the first reported photon driven fragmentation mechanism that is so characteristically sequential.

2. Correlation of the Photofragmentation with Resonant Electronic Excited States. The REMPI spectra obtained by monitoring $\mathrm{Cr}(\mathrm{Cp})_{2}{ }^{+}, \mathrm{Cr}(\mathrm{Cp})^{+}$, and $\mathrm{Cr}^{+}$demonstrate the wavelength dependence of the photofragmentation as shown in Figure $2 \mathrm{a}, 2 \mathrm{~b}$, and $2 \mathrm{c}$, respectively. Interestingly, the wavenumber region where the $\mathrm{Cr}(\mathrm{Cp})_{2}{ }^{+}$signal increases dramatically $(\sim 23530$ $\mathrm{cm}^{-1}$ ) is the same as that where the $\mathrm{Cr}^{+}$signal decreases. The relative intensities of the $\mathrm{Cr}(\mathrm{Cp})_{2}{ }^{+}$to $\mathrm{Cr}^{+}$ions in the REMPI spectra are related to the electronic absorption bands of the molecule. ${ }^{39}$ A ligand-to-metal charge transfer (LMCT) band has been reported at the high energy region of the REMPI spectra. A metal centered $\mathrm{d}-\mathrm{d}$ band has been reported in the $22500-$ $23500 \mathrm{~cm}^{-1}$ region where the $\mathrm{Cr}^{+}$ion peak is dominant.

A. Excited States of Chromocene. The electronic absorption spectra in the UV/vis region has been reported for chromocene in isooctane ${ }^{39}$ solution and in a frozen argon matrix. ${ }^{40}$ Similar spectral features were observed in both of the media. The lowest energy peak maximum occurs at $21970 \mathrm{~cm}^{-1}$, has an extinction coefficient of $186 \mathrm{M}^{-1} \mathrm{~cm}^{-1}$ and originates from ${ }^{3} \mathrm{E}_{2}{ }^{\prime} \rightarrow{ }^{3} \mathrm{E}_{1}{ }^{\prime}$, ${ }^{3} \mathrm{E}_{2}{ }^{\prime},{ }^{3} \mathrm{~A}_{1}{ }^{\prime},{ }^{3} \mathrm{~A}_{2}{ }^{\prime}$ transitions. ${ }^{39}$ The ligand-to-metal charge-transfer transition at $29590 \mathrm{~cm}^{-1}$ has an extinction coefficient of 2700 $\mathrm{M}^{-1} \mathrm{~cm}^{-1}$ and is assigned to the ${ }^{3} \mathrm{E}_{2}{ }^{\prime} \rightarrow{ }^{3} \mathrm{E}_{1}{ }^{\prime \prime}$ transition. ${ }^{39}$ 

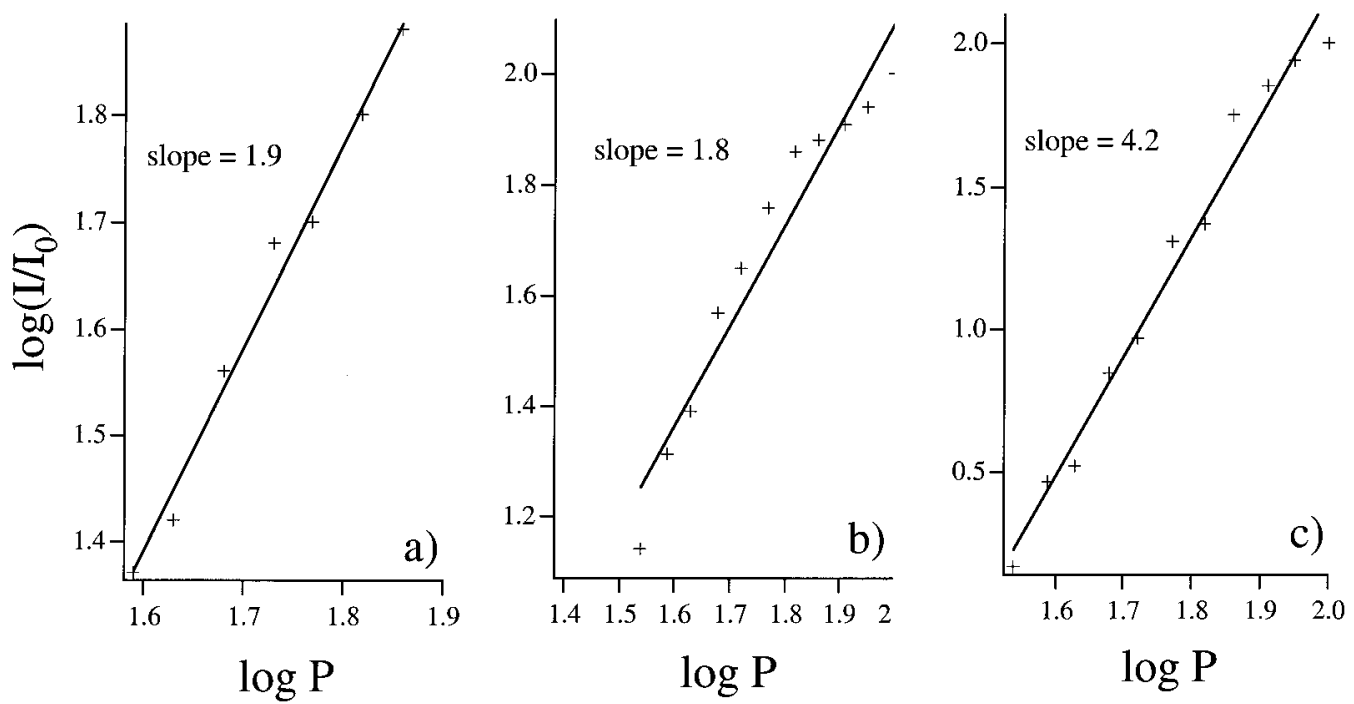

Figure 4. $\log -\log$ plots showing the power dependencies for the molecular ion and metal ion at various wavelengths. The slope of the line gives the observed photon dependence. (a) Photon dependence for the molecular ion using $24260 \mathrm{~cm}^{-1}$ excitation. (b) Photon dependence for the metal ion using $24320 \mathrm{~cm}^{-1}$ excitation. (c) Photon dependence for the metal ion using $23490 \mathrm{~cm}^{-1}$ excitation.

The gas-phase structure of chromocene has eclipsed cyclopentadienyl rings $\left(D_{5 h}\right.$ symmetry). ${ }^{41}$ The ground state of chromocene is ${ }^{3} \mathrm{E}_{2}{ }^{\prime}$ with an electron configuration of $\left(\mathrm{a}_{1}^{\prime}\right)^{1}\left(\mathrm{e}_{2}^{\prime}\right)^{3} \cdot{ }^{41-43}$ Two other orbitals will play a role in the following discussion. The lowest energy completely unoccupied molecular orbital is $\mathrm{e}_{1}{ }^{\prime \prime}$ and the highest energy completely occupied orbital is $\mathrm{e}_{1}{ }^{\prime}$.

The band maximum of the lowest energy spin allowed $d-d$ transition is observed at $22000 \mathrm{~cm}^{-1}$ in isooctane and at 23000 $\mathrm{cm}^{-1}$ in a frozen argon matrix. ${ }^{40}$ The band involves a group of transitions from either the $\mathrm{a}_{1}{ }^{\prime}$ or $\mathrm{e}_{2}{ }^{\prime}$ to the $\mathrm{e}_{1}{ }^{\prime \prime}$ orbital. ${ }^{44}$ The $\mathrm{a}_{1}$ orbital is primarily metal $d_{\mathrm{z}}{ }^{2}$ in character and the $\mathrm{e}_{2}$ orbitals are primarily metal $\mathrm{d}_{x y}$ and $d_{x}^{2}-y^{2}$ in character. The lowest empty orbital, $\mathrm{e}_{1}{ }^{\prime \prime}$, is the antibonding combination of the metal $\mathrm{d}_{x z}$ and $\mathrm{d}_{y z}$ orbitals with the $\mathrm{e}_{1}{ }^{\prime} \pi$-orbitals of the ring. ${ }^{45}$ This molecular orbital is sketched on the left side of Figure 5. The band maximum of the lowest energy charge-transfer band is observed at $29590 \mathrm{~cm}^{-1}$ in isooctane. The transition is from the $1 \mathrm{e}_{1}{ }^{\prime}$ orbital to the $\mathrm{e}_{2}{ }^{\prime}$ orbital. ${ }^{39}$ The $1 \mathrm{e}_{1}{ }^{\prime}$ orbital is predominantly ligand in character, and the transition is characterized as a ligand to metal charge transfer.

B. Bonding Changes in Excited States and Photofragmentation. The bonding and antibonding changes that occur when the $d-d$ and charge-transfer excited states are populated by absorption of the first photon provide a simple explanation for the photofragmentation processes that occur. These processes and the excited states involved are shown in Figure 5.

When the excitation energy is in resonance with the $d-d$ excited state of chromocene, the first photon populates the $d-d$ state. The promotion of an electron from the $\mathrm{a}_{1}{ }^{\prime}$ or $\mathrm{e}_{2}{ }^{\prime}$ orbital to the antibonding $\mathrm{e}_{1}{ }^{\prime \prime}$ orbital will weaken the $\mathrm{M}-\mathrm{Cp}$ bond. ${ }^{41}$ The second photon is absorbed by the weakened molecule and causes fragmentation. It cannot cause ionization because the ionization potential of chromocene is $44362 \mathrm{~cm}^{-1}$. ${ }^{43}$ Thus, fragmentation before ionization is the dominant pathway and $\mathrm{Cr}^{+}$dominates the mass spectra. The resonance peaks in the REMPI spectra show that ligand dissociation to form a neutral chromium atom is a favored pathway in this region and that dissociation events occur prior to molecular ionization. The fragments produced from this state include the neutral chromium atom (as indicated by the resonances) and ligand fragments. Subsequent photon absorption ionizes these fragments. The intact parent molecule

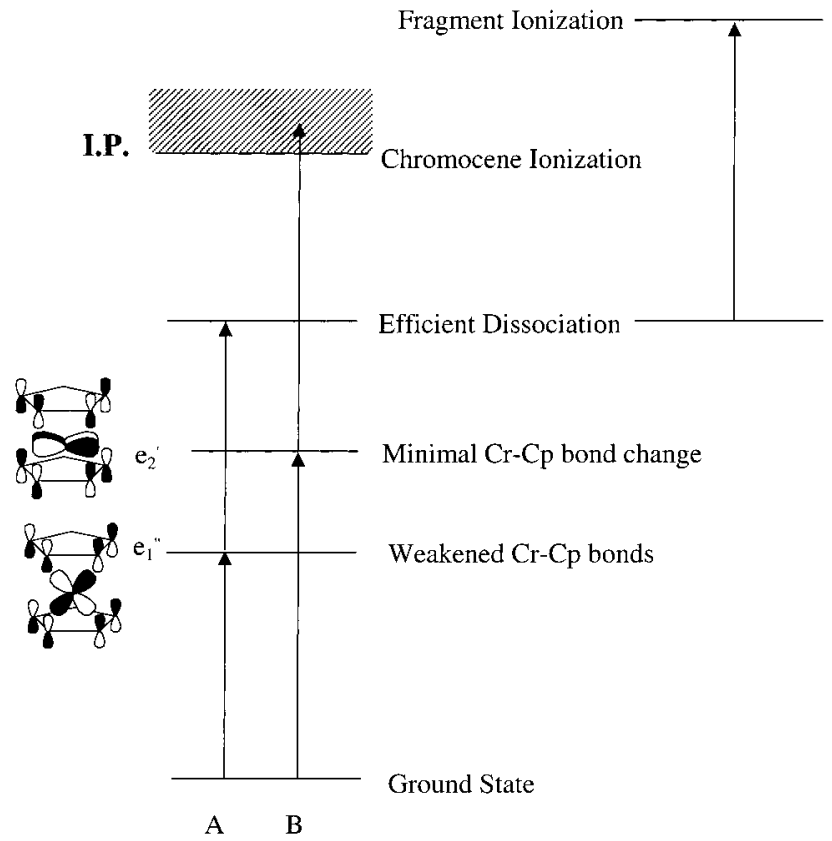

Figure 5. Electronic energy diagram for chromocene with $D_{5 h}$ symmetry. The probability contours of the $\mathrm{e}_{1}{ }^{\prime \prime}$ and $\mathrm{e}_{2}^{\prime}$ molecular orbitals are sketched on the left. The possible processes arising from multiphoton absorption and a proposed explanation for the photofragmentation processes are shown to the right of the different excited states involved. The arrows above A represent the processes when the first photon is in resonance with the $\mathrm{d}-\mathrm{d}$ state, and the arrows above B represent the processes when the first photon is in resonance with the LMCT state.

peaks are at a minimum, probably because the parent cannot remain intact long enough to be ionized and observed.

In contrast, when the excitation is in resonance with the charge transfer state, little bond weakening occurs. The oneelectron transition promotes an electron from an orbital that is primarily localized on the ligand to one that is primarily metal $\mathrm{d}$ orbital in character and slightly metal-ligand bonding. The second photon is absorbed by a molecule that has metal-ligand bonds relatively unchanged from that of the ground-state molecule; fragmentation is minimal. In addition, the combined energy of the two photons is above the ionization potential of the molecule. Thus, ionization of the intact molecule is an important photoprocess and the most intense peak in the mass 

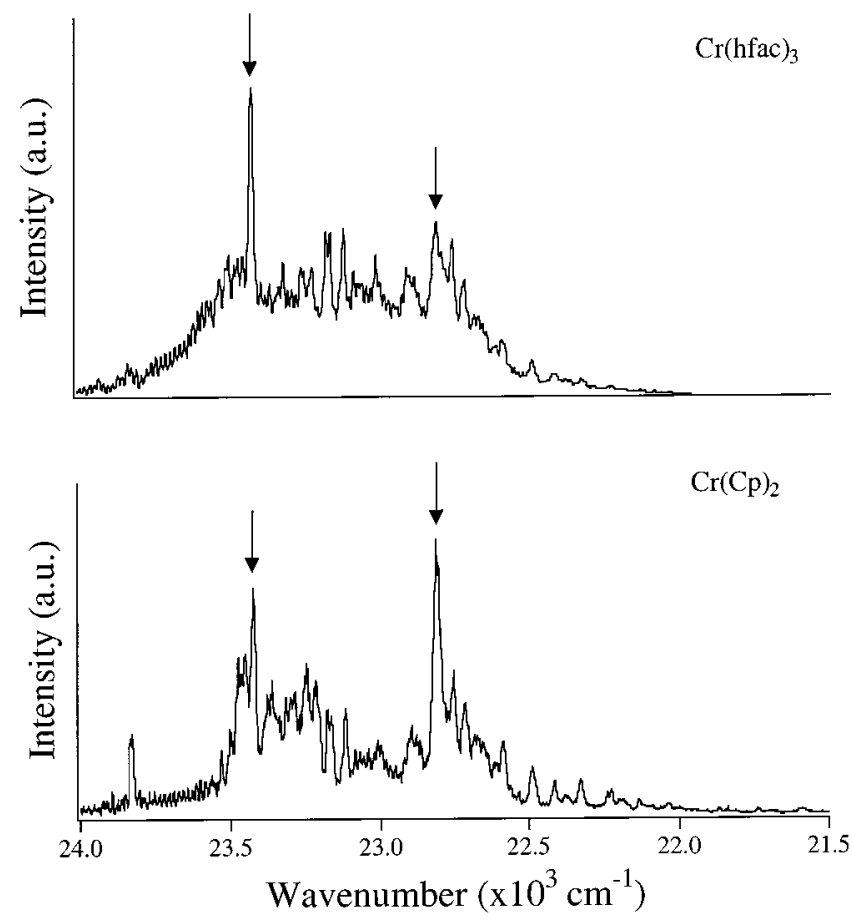

Figure 6. REMPI spectra monitoring the $\mathrm{Cr}^{+}$signal resulting from excitation of (a) $\mathrm{Cr}(\mathrm{hfac})_{3}$ and (b) $\mathrm{Cr}(\mathrm{Cp})_{2}$. The two sharp peaks appearing in both spectra at 23430 and $22810 \mathrm{~cm}^{-1}$ have been previously assigned to $\mathrm{Cr}$ atom transitions.

spectrum is that from the parent ion. However, fragmentation also occurs; the intensity of the $\mathrm{Cr}(\mathrm{Cp})^{+}$ion is about one-half that of the molecular ion, and chromium ion intensity is slightly less than that of the parent ion.

It is important to note that in each region both the $\mathrm{Cr}^{+}$and the $\mathrm{Cr}(\mathrm{Cp})_{2}{ }^{+}$ions are always observed, but the intensities of the fragments fluctuate dramatically within each band. The presence of both ions is understandable because there is overlap between the absorption bands of the molecule.

3. Chromium Atom Resonances. The REMPI spectra that are obtained by monitoring the chromium ion contain sharp peaks. These peaks are observed in all of the wavelength regions that are studied. In addition, sharp losses of intensity or "dips" at the same wavenumber as the peaks are observed in some of the REMPI spectra obtained by monitoring the parent ion or the mono-ligated fragment.

The sharp peaks in the spectra that are obtained when $\mathrm{Cr}^{+}$is monitored (Figure 2c) are assigned to atomic resonances of neutral $\mathrm{Cr}$ and possibly to atom-like absorptions by a molecule in an excited state in which the metal atom is very weakly associated with the ligand. The assignment of most of these sharp peaks to atomic resonances of neutral $\mathrm{Cr}$ is further confirmed by comparing the REMPI spectra obtained monitoring $\mathrm{Cr}^{+}$to that obtained from the photolysis of a different chromium-containing molecule, $\mathrm{Cr}(\mathrm{hfac})_{3}$. The spectrum obtained from $\mathrm{Cr}(\mathrm{hfac})_{3}$ is compared to that from chromocene in Figure 6. There are many peaks in common in the two spectra, supporting the assignment of the peaks to $\mathrm{Cr}$ atom resonances. The two most intense peaks at 23430 and $22810 \mathrm{~cm}^{-1}$ have previously been assigned to $\mathrm{Cr}$ atom transitions ${ }^{46}$ and are due to the ${ }^{3} \mathrm{H}_{6}^{\circ}(4 \mathrm{p}) \rightarrow{ }^{3} \mathrm{G}_{5}(4 \mathrm{~s})$ and ${ }^{5} \mathrm{~F}_{4}^{\circ}(4 \mathrm{p}) \rightarrow{ }^{5} \mathrm{D}_{4}\left(4 \mathrm{~s}^{2}\right)$ transitions.

Careful inspection of Figure 6 at $23830 \mathrm{~cm}^{-1}$ shows a dip in the $\mathrm{Cr}(\mathrm{Cp})_{2}{ }^{+}$spectrum that corresponds to a peak in the $\mathrm{Cr}^{+}$ spectrum. The effect on the intensities of fragments observed in the mass spectra when the excitation is off and on a $\mathrm{Cr}$ resonance is shown in Figure $3 \mathrm{a}$ and $3 \mathrm{~b}$, respectively. Two possible explanations for this behavior are (a) inner filter effects that decrease the amount of photons available for $\operatorname{Cr}(\mathrm{Cp})_{2}$ ionization after $\mathrm{Cr}$ has absorbed photons and (b) neutralization of chromocene ions by electrons released from chromium atoms. Absorption of photons by the metal atom at resonant frequencies may be so efficient that the number of photons available for other photoprocesses such as forming the molecular ion may not be sufficiently large. Another possibility is that during resonant ionization of neutral $\mathrm{Cr}$ atoms, the electrons that are produced are captured by positively charged fragments. The result would be the neutralization of these ions rendering them undetectable by mass spectroscopy.

\section{Summary}

The gas phase laser photochemistry of chromocene is strongly wavelength dependent. The most important photoproduct that is detected by mass spectroscopy when the molecule is irradiated at energies less than about $23530 \mathrm{~cm}^{-1}$ is the $\mathrm{Cr}^{+}$ion. The REMPI spectrum contains numerous intense sharp lines in the region between 22000 and $23530 \mathrm{~cm}^{-1}$ and a relatively featureless broad band at lower energies. Surprisingly, in the region greater than $23530 \mathrm{~cm}^{-1}$, the most prominent photoproduct is the $\mathrm{Cr}(\mathrm{Cp})_{2}{ }^{+}$ion. This result is in contrast to the multiphoton ionization mass spectroscopic results of all of the other metallocenes that have been studied to date where the metal ion always dominates. The maximum reported ratio of intact metallocene ion to metal ion is 0.005 to 1 for nickelocene. In the case of chromocene, the maximum ratio in the wavelength region studied is 1.3 to 1 at $24390 \mathrm{~cm}^{-1}$ excitation. The wavelength dependence is correlated with both the bonding changes that occur in the initially populated excited states and the ionization energy of the molecule. When the initially populated state is the ligand to metal charge transfer state, the first photon causes minimal bond weakening and the second photon excites the intact molecule above the ionization continuum, resulting in efficient ionization of the parent molecule. When the initially populated state is a lower energy ligand field state, significant bond weakening occurs and absorption of a second photon results in significant photodissociation prior to ionization producing intense fragment peaks dominated by the metal ion peak. The intensity ratio of the parent ion to chromium ion in this case never exceeds 0.16:1. The sharp lines in the REMPI spectrum that are observed when the $\mathrm{Cr}^{+}$ion is monitored are assigned to chromium atom resonances. Sharp dips that are observed in the REMPI spectra when other ions are monitored are attributed to either a type of inner filter effect or to electron capture by the other ions.

Acknowledgment. This work was made possible by a grant from the National Science Foundation (NSF Grant No. CHE 9816552).

\section{References and Notes}

(1) Morosanu, C. E. Thin Films by Chemical Vapor Deposition; Elsevier: New York, 1990. 992.

(2) Eden, J. G. Photochemical Vapor Deposition; Wiley: New York,

(3) Hitchman, M. L.; Jensen, K. F. Chemical Vapor Deposition: Principles and Applications; Academic Press: San Diego, 1993.

(4) Kodas, T. T.; Hampden-Smith, M. J. The Chemistry of Metal CVD; Weinheim: New York, 1994.

(5) Braichotte, D.; Garrido, C.; van den Bergh, H. Appl. Surf. Sci. 1990, $46,9-18$.

(6) Cheon, J.; Talaga, D. S.; Zink, J. I. Chem. Mater. 1997, 9, 12081212.

(7) Cheon, J.; Talaga, D. S.; Zink, J. I. J. Am. Chem. Soc. 1997, 119 , $163-168$. 
(8) Jackson, R. L. Acc. Chem. Res. 1992, 25, 581-586.

(9) Smalley, R. E.; Wharton, L.; Levy, D. H. Acc. Chem. Res. 1977, 10, 139-145.

(10) Willwohl, H.; Wolfrum, J. Appl. Surf. Sci. 1992, 54, 89-94.

(11) Cheon, J.; Guile, M.; Muraoka, P.; Zink, J. I. Inorg. Chem. 1999, $38,2238-2239$.

(12) Muraoka, P.; Byun, D.; Zink, J. I. J. Am. Chem. Soc. 2000, 122, $1227-1228$

(13) Cheon, J.; Zink, J. I. J. Am. Chem. Soc. 1997, 119, 3838-3839.

(14) Talaga, D. S.; Hanna, S. D.; Zink, J. I. Inorg. Chem. 1998, 37, 2880-2887.

(15) Talaga, D. S.; Zink, J. I. Inorg. Chem. 1996, 35, 5050-5054.

(16) Bar, R.; Heinis, T.; Nager, C.; Jungen, M. Chem. Phys. Lett. 1982, 91, 440-442.

(17) Braun, J. E.; Neusser, H. J.; Harter, P.; Stockl, M. J. Phys. Chem. A 2000, 104, 2013-2019.

(18) Engelking, P. C. Chem. Phys. Lett. 1980, 74, 207-210.

(19) Leutwyler, S.; Even, U.; Jortner, J. Chem. Phys. Lett. 1980, 74, $11-14$.

(20) Leutwyler, S.; Even, U.; Jortner, J. Chem. Phys. 1981, 58, 409421.

(21) Leutwyler, S.; Even, U.; Jortner, J. J. Phys. Chem. 1981, 85, 30263029 .

(22) Liou, H. T.; Engelking, P. C.; Ono, Y.; Moseley, J. T. J. Phys. Chem. 1986, 90, 2892-2896.

(23) Liou, H. T.; Ono, Y.; Engelking, P. C.; Moseley, J. T. J. Phys. Chem. 1986, 90, 2888-2892.

(24) Nagano, Y.; Achiba, Y.; Kimura, K. J. Phys. Chem. 1986, 90, $1288-1293$.

(25) Niles, S.; Prinslow, D. A.; Wight, C. A.; Armentrout, P. B. J. Chem. Phys. 1992, 97, 3115-3125.

(26) Opitz, J.; Harter, P. Int. J. Mass Spectrom. Ion Processes 1992, 121, 183-199.

(27) Ray, U.; Hou, H. Q.; Zhang, Z.; Schwarz, W.; Vernon, M. J. Chem. Phys. 1989, 90, 4248-4257.
(28) Tyndall, G. W.; Larson, C. E.; Jackson, R. L. J. Phys. Chem. 1989, 93, 5508-5515. 376.

(29) Lubman, D. M.; Jordan, R. M. Rev. Sci. Instrum. 1985, 56, 373-

(30) Wiley: W. C.; McLaren, I. H. Rev. Sci. Instrum. 1955, 26, 11501157.

(31) Gedanken, A.; Robin, M. B.; Kuebler, N. A. J. Phys. Chem. 1982, $86,4096-4107$

(32) Johnson, P. M. Acc. Chem. Res. 1980, 13, 20-26.

(33) Antonov, V. S.; Letokhov, V. S. Appl. Phys. 1981, 24, 89-106.

(34) Ashfold, M. N. R.; Howe, J. D. Annu. Rev. Phys. Chem. 1994, 45, $57-82$.

(35) Lubman, D. M.; Kronick, M. N. Anal. Chem. 1982, 54, 660-665.

(36) Ashfold, M. N. R.; Clement, S. G.; Howe, J. D.; Western, C. M. J. Chem. Soc., Faraday Trans. 1993, 89, 1153-1172.

(37) Schlag, E. W.; Neusser, H. J. Acc. Chem. Res. 1983, 16, 355360 .

(38) Mikami, N.; Ohki, R.; Kido, H. Chem. Phys. 1990, 141, 431-440.

(39) Gordon, K. R.; Warren, K. Inorg. Chem. 1978, 17, 987-994.

(40) Chetwynd-Talbot, J.; Grebenik, P.; Perutz, R. N. Inorg. Chem. 1982, 21, 2647-2657.

(41) Gard, E.; Haaland, A.; Povak, D. P.; RSeip, R. J. Organomet. Chem. 1975, 88, 181-189.

(42) Evans, S.; Green, M. L. H.; Jewitt, B.; King, G. H.; Orchard, A. F. J. Chem. Soc., Faraday Trans. 2 1974, 70, 356-376.

(43) Rabalais, J. W.; Werme, L. O.; Bergmark, T.; Karlsson, L.; Hussain, M.; Siegbahn, K. J. Chem. Phys. 1972, 57, 1185-1192.

(44) Warren, K. D. Inorg. Chem. 1974, 13, 1243-1246.

(45) Brennan, J.; Cooper, G.; Green, J. C.; Payne, M. P.; Redfern, C. M. J. Elect. Spec. Relat. Phenom. 1993, 66, 101-115.

(46) Meggers, W. F.; Corliss, C. H.; Scribner, B. F. Tables of SpectralLine Intensities; National Bureau of Standards: Washington, 1975. 